\title{
RESIDUAL LIFE EVALUATION OF PRESTRESSED REINFORCED CONCRETE HIGHWAY BRIDGES UNDER COUPLED CORROSION-FATIGUE ACTIONS
}

\author{
Jin-song Zhu ${ }^{1,2, *}$, Fa-min Huang ${ }^{1}$, Tong Guo ${ }^{3}$ and Yun-he Song ${ }^{1}$ \\ ${ }^{1}$ School of Civil Engineering, Tianjin University, Tianjin, China. \\ ${ }^{2}$ Key Laboratory of Coast Civil Structure Safety (Tianjin University), Ministry of Education, Tianjin, China. \\ ${ }^{3}$ School of Civil Engineering, Southeast University, Nanjing, China \\ *(Corresponding author: E-mail: jszhu@tju.edu.cn)
}

\begin{abstract}
To evaluate the residual life of prestressed reinforced concrete (PSC) highway bridges in coastal environment, the residual life analysis method of PSC highway bridges under coupled corrosion-fatigue effects is proposed. The multi-scale finite element model of the bridge is employed to perform the detailed stress analysis. The vehicle-bridge coupling vibration analysis is performed to obtain the stress impact coefficients and stress histories of key prestressing strands under the standard AASHTO fatigue truck model. A pit corrosion model is adopted to get stress concentration factors of prestressing strands induced by corrosion. A comprehensive analysis approach is proposed to determine stress amplitudes of key prestressing strands under coupled corrosion-fatigue actions. The S-N curve and the traffic conditions are integrated to determine the service life of the weakest prestressing strand, which is characterized as the service life of the bridge. The effectiveness of the methodology framework is demonstrated on a large-span continuous PSC box-girder bridge.
\end{abstract}

Keywords: Prestressed reinforced concrete bridges, Coupled corrosion-fatigue actions, Residual life, Multi-scale finite element model

DOI: $10.18057 /$ IJASC.2015.11.3.10

\section{INTRODUCTION}

Prestressed reinforced concrete (PSC) bridges in coastal environment are exposed to the deterioration risk by fatigue loads as well as corrosion from the environmental medium. The formation and growth of pits in steel are influenced by both a corrosive environment and cyclic loads, which becomes a coupled damage mechanism of bridges and may cause load-carrying capacity decrease and sudden failure of bridges without any warnings [1].

In the last decades, large research efforts were made on predicting the fatigue reliability, the residual life or the performances of bridges due to the corrosion and/or fatigue loads. However, limited studies investigated the life-cycle performance of bridges under the coupled corrosion-fatigue deterioration processes. Emilio et al. [2] proposed a probabilistic lifetime assessment method of reinforced concrete (RC) structures, in which both corrosion and fatigue effects were combined. The method was validated on a simple supported RC bridge. Dong [3] investigated experimentally the fatigue and bonding performances of corroded RC members. Peng et al. [4] investigated the bonding performance between bars and concrete under fatigue loads. They selected the impressed current corrosion testing to study 13 steel bars with strain gauges which were placed in a machined axial cavity. From their study, the relationship between the cycle numbers of fatigue loads, the amount of corrosion and the bond-slip of bars and concrete were found. Ahn and Reddy [5] evaluated the durability of marine concrete structures subjected to fatigue loads. The accelerated fatigue tests were carried out on full- and half-size RC specimens with three different water cement ratios. Al-Hammoud et al. [6] investigated the fatigue bond 
behavior of corroded steel RC beams by the tests of nine members. Shi et al. [7] investigated the bond degeneration at the bar-concrete interface under variable fatigue loads. Fang et al. [8] carried out tests for bond stress-slip response of corroded reinforcement and concrete under cyclic loads. Siebren et al. [9] presented the periodic overload and corrosion-fatigue resistance of machined specimens made of two corrosion resistant reinforcing steels, MMFX micro composite and 316LN stainless steel. Series of constant amplitude and periodic overload tests were performed in laboratory air and in an aqueous $3.5 \%$ by weight $\mathrm{NaCl}$ solution from which the fatigue resistance of these materials was compared with conventional reinforcing steel. However, reports describing how to directly and effectively evaluate the residual life for PSC bridges under the coupled corrosion-fatigue action are very rare.

This paper outlines a comprehensive method on evaluation of the residual life of PSC bridges under coupled corrosion-fatigue actions. Initially, a multi-scale finite element model of a bridge is created to perform detailed stress analysis. Stress impact coefficients and stress histories of key prestressing strands are obtained from the vehicle-bridge coupling vibration analysis in which the standard fatigue truck model specified in AASHTO are considered. A pit corrosion model is adopted to determine stress concentration factors of the prestressing strands due to corrosion. A comprehensive analysis method is proposed to compute stress amplitudes of key prestressing strands under coupled corrosion-fatigue effects. Consequently, the S-N curve and the traffic condition are integrated to find the service life of the weakest strand, which is characterized as the service life of the bridge. Finally, the effectiveness of the methodology framework is demonstrated on a large-span continuous PSC bridge, and several important observations are summarized.

\section{VEHICLE-BRIDGE COUPLING VIBRATION ANALYSIS}

\subsection{Multi-scale Finite Element Model of the PSC Bridge}

In general, structural analysis is usually carried out at different scale levels for different purposes. For a large structure, the size of the model beam element is usually at the level of meter for global structural analysis. Meanwhile, the beam element is also adopted at the centimeter level of component scale for nominal stress analysis. Furthermore, the scale of material points, usually modelled with shell or solid elements, is commonly less than the level of a millimeter for the local detailed hot-spot stress analysis. In order to achieve the magnitude of accuracy and efficiency between global finite element analysis and local refined stress analysis, a multi-scale finite element modelling technology is adopted in this study [10]. There are two key issues on establishing a multi-scale finite element model, the selection of key parts and the assembly of sub-models. Those parts of the structure which are vulnerable to damages are determined by the structural static analysis. In these key parts, solid elements are used to simulate the post-damaged performance, and other parts are designed from beam elements. In the interfaces between beam-element sub-models and solid-element sub-models, the master and slave nodes are defined to assemble the sub-models.

The general method of coupling elements of dissimilar dimensions via constraint equations has been proposed by McCune et al. [10], which is based on equating the work done on both sides of the interface of different elements. A basic requirement of the method is the knowledge of the stress distribution at the interface which can be obtained from the results of beam theory. Constraint equations are also adopted to connect the master and slave nodes herein, as shown in Figure 1.

The constraint equation method refers to a kind of linear equation connecting degrees of freedom (see Eq. (1)). 
Const $=\sum_{i=1}^{N}(C(i) \cdot U(i))$

where $U(i)$ is the variable of the $i^{\text {th }}$ degree of freedom; C $(i)$ is the coefficient of $U(i)$; and $N$ is the number of degrees of freedom.

If the constraint equations have been determined, they are successfully incorporated in the finite element formulation by standard methods such as Lagrange multiplier or penalty function methods. In the present study, constraint equations can be easily implemented in the general-purpose finite element software ANSYS [11] by *CERIG command.

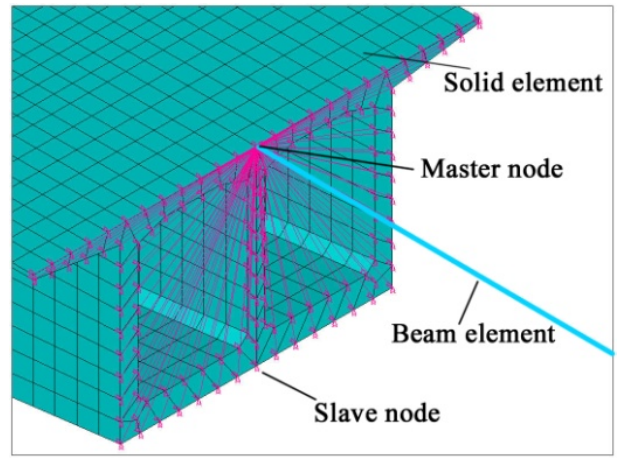

Figure 1. Details of Assembly Models

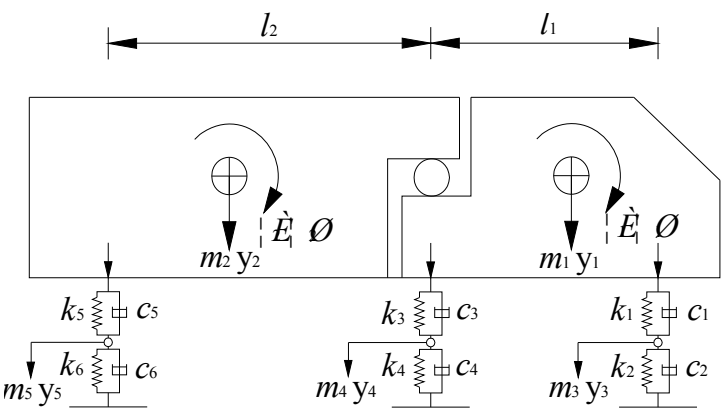

Figure 2. Model of AASHTO Fatigue Truck

\section{$2.2 \quad$ Vehicle Model}

The triaxial fatigue vehicle model of the American Association of State Highway and Transportation Officials (AASHTO) [12] is adopted in the present study. Taking the mass and rigidness of axles into consideration, it simplifies the head and body of the truck into two masses, respectively. There are seven independent degrees of freedom in total, as shown in Figure 2. The parameters of AASHTO fatigue truck are listed in Table 1.

Table 1. Parameters of AASHTO Fatigue Truck

\begin{tabular}{|c|c|c|c|}
\hline Vehicle parameters & Value & Vehicle parameters & Value \\
\hline vehicle head mass $m_{1}$ & $2612 \mathrm{~kg}$ & $2^{\text {nd }}$ axle suspended mass $m 4$ & $808 \mathrm{~kg}$ \\
\hline $\begin{array}{c}\text { vehicle head pitching rotational } \\
\text { inertia } \theta_{1}\end{array}$ & $2022 \mathrm{~kg} \cdot \mathrm{m}^{2}$ & $2^{\text {nd }}$ axle upper spring stiffness $k_{3}$ & $1903172 \mathrm{~N} / \mathrm{m}$ \\
\hline $\begin{array}{l}\text { vehicle head rolling rotational } \\
\text { inertia } \omega 1\end{array}$ & $8544 \mathrm{~kg} \cdot \mathrm{m}^{2}$ & $\begin{array}{l}2^{\text {nd }} \text { axle upper damping constants } \\
\qquad c_{3}\end{array}$ & $7882 \mathrm{~N} \cdot \mathrm{s} / \mathrm{m}$ \\
\hline vehicle body mass $m_{2}$ & $26113 \mathrm{~kg}$ & $2^{\text {nd }}$ axle lower spring stiffness $k_{4}$ & $3503307 \mathrm{~N} / \mathrm{m}$ \\
\hline $\begin{array}{l}\text { vehicle body pitching rotational } \\
\text { inertia } \theta_{2}\end{array}$ & $33153 \mathrm{~kg} \cdot \mathrm{m}^{2}$ & $2^{\text {nd }}$ axle lower damping constants & $2000 \mathrm{~N} \cdot \mathrm{s} / \mathrm{m}$ \\
\hline $\begin{array}{c}\text { vehicle body rolling rotational } \\
\text { inertia } \omega_{2}\end{array}$ & $181216 \mathrm{~kg} \cdot \mathrm{m}^{2}$ & $3^{\text {rd }}$ axle suspended mass $m_{5}$ & $653 \mathrm{~kg}$ \\
\hline 1 st axle suspended mass $m_{3}$ & $490 \mathrm{~kg}$ & $3^{\text {rd }}$ axle upper spring stiffness $k_{5}$ & $1969034 \mathrm{~N} / \mathrm{m}$ \\
\hline 1 st axle upper spring stiffness $k_{1}$ & $242604 \mathrm{~N} / \mathrm{m}$ & $\begin{array}{l}3^{\text {rd }} \text { axle upper damping constants } \\
c_{5}\end{array}$ & $7182 \mathrm{~N} \cdot \mathrm{s} / \mathrm{m}$ \\
\hline $\begin{array}{l}\text { 1st axle upper damping } \\
\text { constants } c_{1}\end{array}$ & $2190 \mathrm{~N} \cdot \mathrm{s} / \mathrm{m}$ & $3^{\text {rd }}$ axle lower spring stiffness $k_{6}$ & $3507429 \mathrm{~N} / \mathrm{m}$ \\
\hline
\end{tabular}




\begin{tabular}{cccc}
\hline $\begin{array}{c}\text { 1st axle lower spring stiffness } k_{2} \\
\begin{array}{c}\text { 1st axle lower damping } \\
\text { constants } c_{2}\end{array}\end{array}$ & $875082 \mathrm{~N} / \mathrm{m}$ & $3^{\text {rd }}$ axle lower damping constants & $2000 \mathrm{~N} \cdot \mathrm{s} / \mathrm{m}$ \\
$c_{6}$ & $2000 \mathrm{~N} \cdot \mathrm{s} / \mathrm{m}$ & vehicle length $l_{1}+l_{2}$ & $(4+4.5) \mathrm{m}$ \\
\hline
\end{tabular}

Table 2. Road Surface Roughness Classifications

\begin{tabular}{cc}
\hline $\begin{array}{c}\text { Road-roughness } \\
\text { classifications }\end{array}$ & $\phi\left(n_{0}\right)$ \\
\hline Very good & $2 \times 10^{-6} \leq \phi\left(n_{0}\right)<8 \times 10^{-6}$ \\
Good & $8 \times 10^{-6} \leq \phi\left(n_{0}\right)<32 \times 10^{-6}$ \\
Average & $32 \times 10^{-6} \leq \phi\left(n_{0}\right)<128 \times 10^{-6}$ \\
Poor & $128 \times 10^{-6} \leq \phi\left(n_{0}\right)<512 \times 10^{-6}$ \\
Very poor & $512 \times 10^{-6} \leq \phi\left(n_{0}\right)<2048 \times 10^{-6}$ \\
\hline
\end{tabular}

\subsection{Roadway Profile}

The road surface condition is a very important factor that affects the dynamic responses of the bridge and vehicles. Deterioration of bridge road surfaces can occur at both the bridge deck and joints for numerous reasons, such as aging, varying environmental conditions, corrosion and the increased gross vehicle weight.

The road surface roughness is generally defined as an expression of irregularities of the road surface. The research conducted by Zhang and Cai [13] shows that the road surface roughness is usually assumed as a zero-mean stationary Gaussian random process and it could be generated through an inverse Fourier transformation as Eq.(2).

$r(x)=\sum_{k=1}^{N} \sqrt{2 \phi\left(n_{k}\right) \Delta n} \cos \left(2 \pi n_{k} x+\theta_{k}\right)$

where $r(x)$ is the roadway surface roughness; $\phi(\cdot)$ is the power spectral density function $\left(\mathrm{m}^{3} / \mathrm{cycle} / \mathrm{m}\right)$ for the road surface elevation; $n_{k}$ is the wave number $(\mathrm{cycle} / \mathrm{m}) ; \Delta n$ is the frequency increment and $\theta_{k}$ is the random phase angle uniformly distributed from 0 to $2 \pi$. The power spectral density function $\phi(\cdot)$ is defined as Eq. (3).

$\phi(n)=\phi\left(n_{0}\right)\left(\frac{n}{n_{0}}\right)^{-2}$

where $n$ is the spatial frequency (cycle/m); $n_{0}$ is discontinuity frequency of $1 / 2 \pi\left(\right.$ cycle/m); $\phi\left(n_{0}\right)$ is roadway surface roughness coefficient $\left(\mathrm{m}^{3} / \mathrm{cycle}\right)$, and its value is chosen depending on the road condition. According to the different value of roadway surface roughness coefficient, the roadway surface roughness could be divided into five levels combining Eq. (2) and Eq. (3), as listed in Table 2.

\subsection{Stress Concentration Factor of Corroded Prestressing Strands}

Under the corrosion environment of chloride salts in coastal areas, the passive films of embeded prestressing stands of PSC bridges are damaged, which induces corrosion uniformly and forms the pits. The stress concentrates around the corrosion pits of prestressing strands in service, which will reduce the load carrying capacity of the bridge sharply. Therefore, the stress concentration effects 
of embedded prestressing strands due to corrosion must be considered for evaluating the residual life of the bridge more practically.

The stress concentration factor affects the fatigue life of the reinforcing steel bars and thus the fatigue life of the PSC bridge. Many factors affect the stress concentration factor and include the geometry of the notch, material type, and especially the pit depth of corrosion. When the geometry of the notch and the mechanical properties are uniform, differences due to corrosion of the reinforcing steel bars will cause different stress concentration factors in different service years.

Shi [14] investigated stress concentration properties of corroded prestressing strands by the meso-scale finite element method. The local stress states of embedded corroded prestressing strands are simulated by assumed corrosion pits on prestressing strands and cracks in the surrounding concrete. The relationships between the stress concentration factor and the corrosion period are formulized for round, oval and triangular corrosion pits, respectively. The stress concentration factors of prestressing strands induced by corrosion pits are defined as Eq. (4) [14].

$\lambda=\left\{\begin{array}{lr}1.045+0.00335\left(t_{1}-t_{0}\right) & \text { for the round pit } \\ 1.039+0.00313\left(t_{1}-t_{0}\right) & \text { for the oval pit } \\ 1.095+0.00234\left(t_{1}-t_{0}\right) & \text { for the triangular pit }\end{array}\right.$

where $t_{0}$ is the reinforcement corrosion period (years) and $t_{1}$ is the service life of the bridge (years).

\subsection{Impact Factor}

To predict the dynamic responses of bridges resulting from a moving vehicle is a significant problem in bridge design. Most design codes assign an approximate quantity for the dynamic response for a normal design procedure, amplifying the static response with an impact factor $\mu$. The impact factor is defined as Eq. (5).

$\mu=\frac{R_{d \max }-R_{s \max }}{R_{s \max }}$

where $R_{d \max }$ and $R_{s \max }$ are the maximum dynamic and static responses of the bridge, respectively.

In order to investigate the variability of impact factors of different parts in the bridge resulting from a moving vehicle, the vehicle-bridge coupling vibration analysis program developed by the same research group [15] is applied to calculate impact factors of the bridge under dynamic loads.

\subsection{Stress Amplitude}

The bridge suffers from the cyclic load and corrosion environment during service stage. As the damage of PSC bridges is usually caused by the failure of corrosion prestressing stands under the coupled corrosion-fatigue actions, the residual life of the weakest prestressing strand is used to characterize the residual life of the bridge. Combining the stress concentration of the prestressing strand and the dynamic impact, the stress amplitude of the prestressing strand $S$ induced by one truck passage is expressed as Eq. (6).

$S=\mu \cdot \lambda \cdot \Delta \sigma$

where $\Delta \sigma$ is the original stress amplitude induced by one truck passage. 


\section{RESIDUAL LIFE EVALUATION OF PSC BRIDGES}

\subsection{Residual Life Analysis}

It is extremely difficult to analyze a structure suffering from random loads since the weights, types and speeds of the vehicles on the bridge are different. In addition, the appearing time interval is also random. Thus, it needs to be simplified reasonably by the researcher to find the likely method for meeting the balance of the precision and the efficiency. The AASHTO fatigue vehicle mentioned above is selected as the standard loading model. The maximum stress amplitude of the stress cycle caused one fatigue truck passage is taken into consideration. The cumulated number of truck passages for the future year $t$ can be estimated as Eq. (7) [16].

$$
N_{f}(t)=365 \times A D T T \times \int_{0}^{t}(1+\alpha)^{t} d y=365 \times A D T T \times \frac{(1+\alpha)^{t}-1}{\ln (1+\alpha)}
$$

Where $t$ is the bridge life (years); ADTT is the average daily truck traffic and $\alpha$ is the annual rate of traffic increase.

After stress amplitude $\Delta \sigma$ is obtained, the number of stress cycles $N$ in the whole life cycle of the bridge can be calculated according to the $S$ - $N$ curve [17] of the prestressing strand (see Eq. (8)).

$\lg N=8.08-3.5 \lg S$

If $N_{f}(t)=N$, the bridge life limit is reached, and then the theoretic service life of bridge could be predicted by Eq. (9).

$t_{T}=\frac{\ln \left\{\frac{10^{8.08} \cdot \ln (1+\alpha)}{365 \cdot A D T T \cdot[\mu \cdot \lambda \cdot \Delta \sigma]^{3.5}}+1\right\}}{\ln (1+\alpha)}$

Therefore, the residual life of the bridge is equal to $t_{T}-t$.

\subsection{Procedure of Residual Life Evaluation of PSC Bridges}

The proposed procedure for the residual life evaluation of PSC highway bridges (as shown in Figure 3) is summarized as following:

Step 1: establish the multi-scale finite element model of the bridge;

Step 2: obtain the hot spot stress history from the finite element analysis under one truck passage; Step 3: obtain impact coefficients of prestressing strands by the vehicle-bridge coupling vibration analysis;

Step 4: obtain the stress concentration factor from the pit corrosion model of prestressing strands; Step 5: obtain stress amplitudes of prestressing strands by combining Step 2 to Step 4;

Step 6: determine the life of the weakest prestressing strand basing on the $S-N$ curve and the traffic volume, which characterizes as the total service life of the bridge;

Step 7: calculate the residual life of the bridge according to its service time till now. 


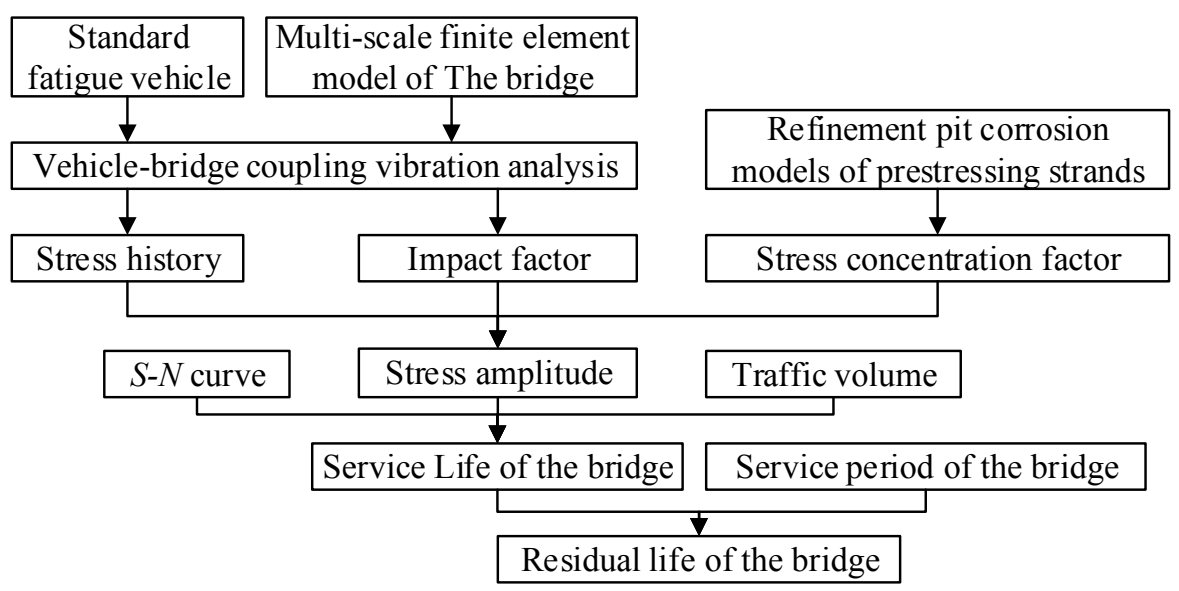

Figure 3. Flowchart of Residual Life Evaluation of PSC Bridges

\section{ILLUSTRATIVE EXAMPLE}

\subsection{Bridge Description}

A three-span continuous trapezoidal box-girder bridge located at Binhai New Area of Tianjin, China, is used to illustrate the application of this proposed method. The span layout of the bridge is $90 \mathrm{~m}+160 \mathrm{~m}+90 \mathrm{~m}$. The width of the bridge is $20.5 \mathrm{~m}$. The maximum and minimum depths of the box-girder on the main span are $9.5 \mathrm{~m}$ and $3.5 \mathrm{~m}$, respectively. The box-girder is the straight web single box with double chambers. The bottom and top widths of the box-girder are $12.5 \mathrm{~m}$ and $20.5 \mathrm{~m}$, respectively. The flange of the box-girder is $4.0 \mathrm{~m}$ at each side. The box-girder is a three-dimension PSC structure. The bridge was designed according to the China Code (JGJ D62-2004) for the Highway-I live load. The width of lanes was designed for meeting the demand of the vehicle speed $80 \mathrm{~km} / \mathrm{h}$. The designed service life of the bridge is 100 years, and it was open to the public in May 2008.

The multi-scale finite element model of the bridge is built as shown in Figure 4. Considering the mechanical characteristics of the bridge in service, the midspan and the negative moment region are the vulnerable areas. Therefore, refined finite element models with solid elements are built for them and beam element models are built for the rest parts. The middle section of side span (Section 1), two end sections of the negative moment region (Section 2 and 3), and middle section of mid-span (Section 4) are mainly analyzed herein as shown in Figure 4.

The midlines of the decks and bottom plates, webs and corners of the box-girder are vulnerable locations analyzed from the angle of the section [18]. The prestressing strands of these locations should be primarily focused in the present study. These critical prestressing strands are denoted in Figure 5.

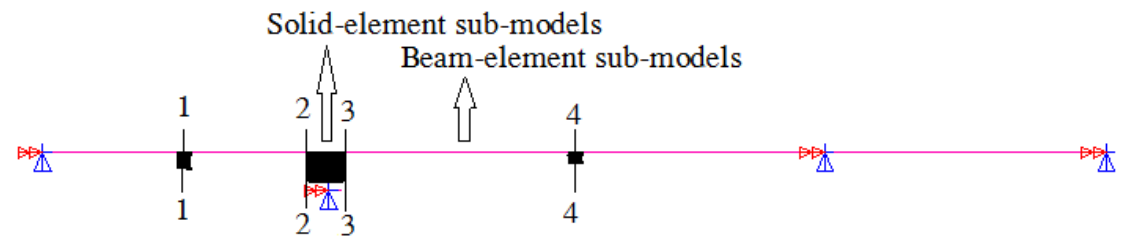

Note: 1, 2, 3 and 4 denote locations of the concerned sections.

Figure 4. Multi-scale Finite Element Model of the Concerned Bridge 


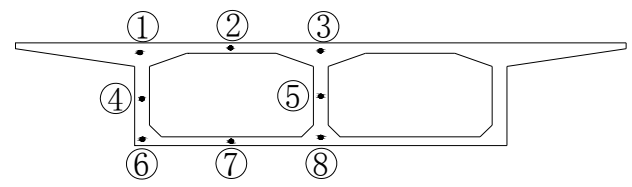

(a) Mid-span cross-section

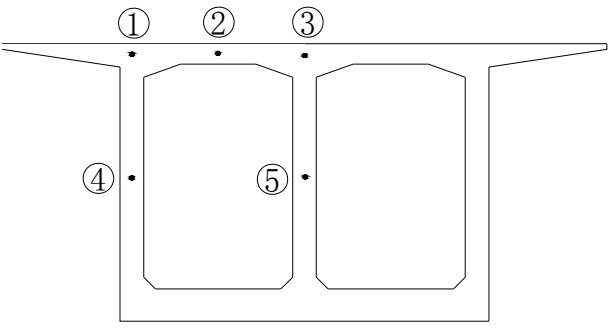

(b) Support cross-section

Figure 5. Typical Locations of the Vulnerable Prestressing Strands

\subsection{Results and Discussions}

\subsubsection{Residual lives of the concerned prestressing strands in different sections}

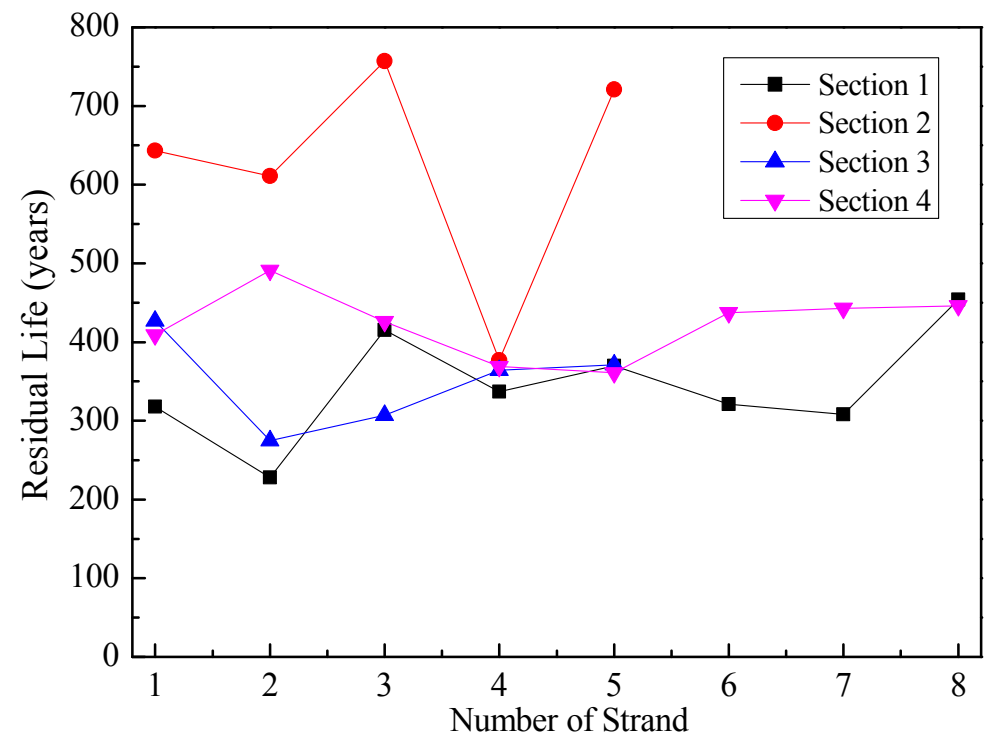

Figure 6. The Prestressing Strand lives on Different Sections

Residual lives of the prestressing strands at four different sections were predicted to characterize the residual life of the bridge as shown in Figure 6 . The results were obtained at an $80 \mathrm{~km} / \mathrm{h}$ vehicle speed and an 'average' road surface roughness condition. It can be seen that the predicted residual life of the bridge is longer than the design life, which proves that the bridge will not fail under the coupled corrosion-fatigue actions. It also can be seen from Figure 6 that the life of the prestressing strand at the center of the deck of the chamber is relatively shorter. One possible reason is that the deck bears vehicle loads directly and works in the repeated tension and compression stress state with large stress amplitude.

\subsubsection{Effect of the roadway surface roughness on the residual life of the bridge}

The deck surface suffers from the wheels of vehicle directly, which induces its deterioration during the service stage of the bridge. The deck surface roughness is a major factor in vehicle/bridge interaction [12]. To evaluate the effect of roadway surface roughness on the residual life of the bridge, five different road surface roughnesses are considered at an $80 \mathrm{~km} / \mathrm{h}$ vehicle speed. As shown in Figure 7, the residual life of the bridge decreases as the road surface roughness increases. The residual life is $30 \%$ shorter when the 'very poor' road surface roughness in 'very poor' 
condition than that when the road surface roughness in 'very good' condition, which proves that road surface profile has a significant effect on the residual life of the bridge. When the road is rough, the vehicle cannot move steadily and bumps sharply, which results in the increase of the impact force on the bridge and the stress amplitude of the prestressing strand.

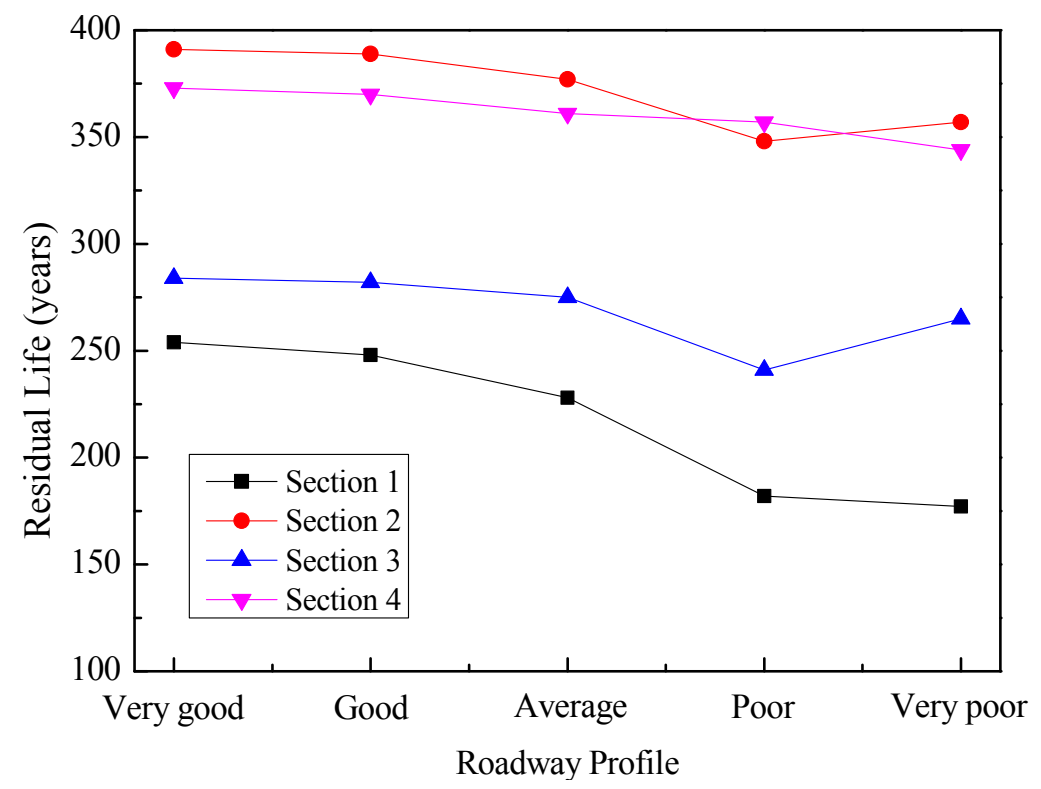

Figure 7. Effect of the Roadway Surface Roughness on the Residual Life

\subsubsection{Effect of the vehicle speed on the residual life of the bridge}

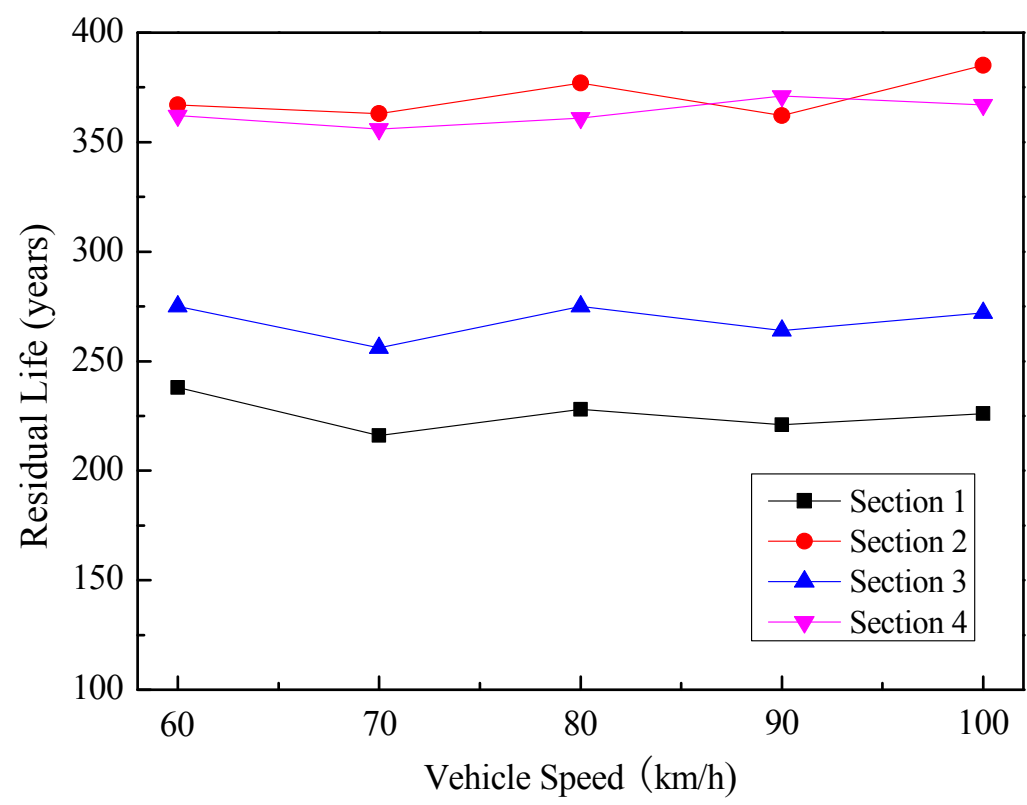

Figure 8. Effect of the Vehicle Speed on the Residual Life 
As stated earlier by many researchers, the vehicle speed has an ambiguous effect on the impact factor of highway bridges, and the resonance will happen when the vehicle speed reaches a certain value $[13,19]$. To evaluate the effect of the vehicle speed on the residual life of the bridge, five different vehicle speeds are considered at an "average" road surface roughness. There is not obvious discrepancy of residual lives of the bridge for the five different vehicle speeds at an "average" road surface roughness as shown in Figure 8. Similar results can also be observed for the fatigue life of a PSC multi-girder bridge in the previous study [19]. Attention should be paid to the middle of the bridge side spans because its life span is much shorter. It also can be seen that the life of the prestressing strand in the negative moment region prolongs with the increase of the vehicle speed, since with increase of the vehicle speed, the inertia of the vehicle will increase, which makes vehicle move steadier to bring less impact on the bridge.

\section{CONCLUSIONS}

This paper proposed a method to evaluate the residual life of PSC highway bridges under the coupled corrosion-fatigue actions. From the present study, the following conclusions are drawn:

(1) The most vulnerable area is the deck of the chamber in the box-girder highway bridge.

(2) The residual life of the prestressing reinforced concrete highway bridge is affected slightly by the vehicle speed.

(3) The road surface roughness has more significant negative impact on the residual life of the bridge while the vehicle runs under relatively lower speed.

(4) The present method to some extent is universal, and researchers can adopt different analysis softwares and identification principles according to the actual situation. Based on the complexity of the operational environment, such as overload or accidental damage, more refined analysis should be considered for the proposed method, and this remains to be investigated in future studies.

\section{ACKNOWLEDGMENTS}

The financial support from the National Science Fund of China (51178305), the Tianjin Research Program of Application Foundation and Advanced Technology (14JCYBJC21500), the Natural Science Foundation of Jiangsu (BK2011611) and the Fok Ying Tung Education Foundation (No.131074) are gratefully acknowledged.

\section{REFERENCES}

[1] Lucia, T., and Chen, Liang., “ Numerical Simulation of Inelastic Cyclic Response of HSS Braces upon Fracture”, Advanced Steel Construction, 2014, Vol. 10, No. 4, pp. 442-462.

[2] Emilio, B. A., Philippe, B., Alaa, C. and Mauricio S. S., "Probabilistic Lifetime Assessment of RC Structures under Coupled Corrosion-fatigue Deterioration Processes", Structural Safety, 2009, Vol. 31, No. 1, pp. 84-96.

[3] Dong, F.X., "Experimental Study on Fatigue Performance of Steel Corrosion Concrete Members", Dissertation submitted to Nanjing University of Science and Technology in Conformity with the Requirements for the Degree of Master, 2007. (in Chinese) 
[4] Peng, X.N., Jin, L.Z., Xue, J.Y. and Wei, B.N., "Experimental Study on Bond Performance Deterioration between Corroded Bars and Concrete under Fatigue Loads", Industrial Construction, 2010, Vol. 40, No. 2, pp. 101-104. (in Chinese)

[5] Ahn, W. and Reddy, D.V., "Galvanostatic Testing for the Durability of Marine Concrete under Fatigue Loading", Cement and Concrete Research, 2001, Vol. 31, No. 3, pp. 343-349.

[6] Al-Hammoud, R., Soudki, K. and Timothy, H. T., "Bond Analysis of Corroded Reinforced Concrete Beams under Monotonic and Fatigue Loads", Cement \& Concrete Composites, 2010, Vol. 32, No.3, pp. 194-203.

[7] Shi, Z.F., Cui, C. and Zhou, L.M., "Bond Decay at Bar-concrete Interface under Variable Fatigue Loads", European Journal of Mechanics A/Solids, 2006, Vol. 25, No. 5, pp. 808-818.

[8] Fang, C.Q., Kent, G., Karin, L. and Mario, P., "Effect of Corrosion on Bond in Reinforced Concrete under Cyclic Loading", Cement and Concrete Research, 2006, Vol. 36, No. 3, pp. 548-555.

[9] Siebren, J. D., Trick, J. H. and Colin, M., "Periodic Overload Corrosion Fatigue of MMFX and Stainless Reinforcing Steels", Journal of Materials in Civil Engineering, 2009, Vol. 21, No. 1, pp.1-9.

[10] McCune, R.W., Armstrong, C.G. and Robinson, D.J., "Mixed Dimensional Coupling in Finite Element Models", International Journal for Numerical Methods in Engineering, 2000, Vol. 49, No. 6, pp.725-750.

[11] ANSYS Release 8.1, ANSYS Inc., 2004.

[12] AASHTO. "AASHTO LRFD Bridge Design Specifications 4th Edition", American Association of State Highway and Transportation Officials, Washington, DC, 2007.

[13] Zhang, W. and Cai, C.S., "Fatigue Reliability Assessment for Existing Bridges Considering Vehicle Speed and Road Surface Conditions", Journal of Bridge Engineering, 2012, Vol. 17, No. 3, pp. 443-453.

[14] Shi, X.M., "Study on Life Prediction Method of RC Bridge under Coupled Corrosion-fatigue Effects"(in Chinese), Dissertation submitted to Tianjin University in Conformity with the Requirements for the Degree of Master, 2012.

[15] Zhu, J.S. and Yi, Q., "Bridge-vehicle Coupled Vibration Response and Static Test Data based Damage Identification of Highway Bridges", Structural Engineering and Mechanics, 2013, Vol. 46. No. 1, pp. 75-90.

[16] Kwon, K. and Frangopol, D.M., "Bridge Fatigue Reliability Assessment using Probability Density Functions of Equivalent Stress Range based on Field Monitoring Data", International Journal of Fatigue, 2010, Vol. 32, No.8, pp. 1221-1232.

[17] Paulson, C., Frank, J. K. H. and Breen, J. E., "A Fatigue Study of Prestressing Strand", FHWA Research Report 300-1, Center for Transportation Research, The University of Texas at Austin, Austin, Texas, 1983.

[18] Lee, S.Y. and Yhim, S.S., "Dynamic Behavior of Long-span Box Girder Bridges Subjected to Moving Loads", Numerical Analysis and Experimental Verification, 2005, Vol. 42, No. 18-19, pp. 5021-5035.

[19] Zhu, J.S., Chen, C. and Han, Q.H., "Vehicle-bridge Coupling Vibration Analysis based Fatigue Reliability Prediction of Prestressed Concrete Highway Bridges", Structural Engineering and Mechanics, 2014, Vol. 49, No. 2, pp. 203-223. 